\title{
Investigation and Study on the Design and Construction Status of Spoil Yards in Mountainous Highways
}

\author{
Jian Wang ${ }^{1}$, Wei Zhang ${ }^{2}$ \\ ${ }^{1}$ Research Institute of Highway Ministry of Transport, Beijing, 100086, China \\ ${ }^{2}$ Hangzhou Urban Expressway Co., Ltd; 310024, Hangzhou, China
}

\begin{abstract}
This study conducts field investigation, survey and analysis on the spoil yards in 37 mountainous highways across the country and analyzes the current protection features of the spoil yard projects and the main type, effect and applicability of restoration measures to provide technical support for design and construction.
\end{abstract}

\section{Introduction}

This study investigates the design and construction status of the spoil yards in mountainous highways comprehensively, analyzes the main factors affecting the scale of the spoil yards, finds out the main types and the degree of soil and water loss in the spoil yards as well as the harm to the surrounding environment [1-3], masters the main type, effect and applicability of the current spoil yard project protection and drainage project and sorts out the main problems [4] in the design and construction of the spoil yards to provide technical support for the design and construction of the spoil yard in the mountainous area.

\section{Investigation content}

The main content of the investigation includes,

2.1 characteristics of waste slags in mountainous highways, including investigating basic conditions of mountainous highways (including main technical indicators and main construction scale) and characteristics of the spoil yards (location, quantity, slag quantity, restoration measures, etc.) and performing statistical analysis.

2.2 Current design status of the spoil yards in mountainous highways, including investigating the changes in the spoil yard layout (location, type, floor area and slag quantity) during the design phase of the project, analyzing the main considerations for earthwork vertical deployment at different design phases, the spoil yard design depth and the change reasons and mastering the main difficulties in implementing the design of the spoil yards in the construction phase.
2.3 Current construction status of the spoil yards in mountainous highways, including investigating the spoil yard type, slag characteristics, engineering protection and drainage project, restoration measures and effects, soil and water loss and its hazard form and degree. In addition, the highway spoil yard in construction is subjected to field investigation in the construction mode.

\section{Investigation method}

According to the investigation content, the methods of combining data investigation statistics and analysis, typical investigation and tracking investigation relying on the project spoil yard design and construction whole process are adopted as follows:

- Data investigation statistics and analysis

Taking the mountainous highway construction projects completed since 2000 as the investigation objects, collect and summarize the project delivery acceptance summary report and the completion environmental protection acceptance investigation report, and analyze the relationship between the mountainous highway subgrade earthwork, the bridge and tunnel ratio and the slag quantity to find out the distribution law and the main restoration methods of the current spoil yards in the mountainous highways.

\section{- $\quad$ Typical investigation}

Select the completed highways and the highways under construction from the hilly red soil region of the South, the loess plateau region of the Northwest, the earth and rock mountainous region of the Southwest and the earth and rock mountainous region of the North as the investigation objects and perform field investigation, survey and analytical study one by one.

- $\quad$ Tracking investigation relying on the project spoil yard design and construction whole process

Perform whole-process tracking investigation on the design and construction status of the spoil yards relying 
on the construction of the Yongwu Expressway in Jiangxi.

\section{Investigation results of spoil yards in mountainous highways}

The investigation results of the main technical indicators, construction scale and spoil yards of 37 mountainous highways across the country show that:

\subsection{Earthwork situation on mountainous highways}

\subsubsection{Earthwork volume and slag quantity of highways in different geomorphologic regions}

In this investigation project, there are 3 highways located in the plain rolling terrain area, where the average subgrade earthwork volume per kilometer is about $67,100 \sim 165,500 \mathrm{~m}^{3}$, and the average slag quantity per kilometer is about $15,300 \sim 22,400 \mathrm{~m}^{3}$. Among them, the partial section of Guangzhou-Huizhou Expressway is the six-lane expressway with relatively large average subgrade earthwork volume and slag quantity per kilometer; the majority of the sections of Dongsheng-Sujia River Expressway in Inner Mongolia are in windy and sandy regions with relatively flat terrain and relatively small average earthwork volume per kilometer.

Among the 14 highway projects investigated in the area of mountains and hills, except the Ningqiang-Qipanguan Expressway in Shaanxi with small average subgrade earthwork volume per kilometer due to short mileage and large bridge and tunnel ratio, the average subgrade earthwork volume per kilometer of the other highways is about $108,000 \sim 459,500 \mathrm{~m}^{3}$; the average subgrade earthwork volume per kilometer of the highway projects in the area of mountains and hills is $12,900 \sim 208,700 \mathrm{~m}^{3}$, and the average slag quantity per kilometer varies greatly between different projects. Wherein, the average slag quantity per kilometer of Kunming-Shilin Expressway and Dali-Baoshan Expressway in Yunnan and Sansui-Kaili Expressway is more than $100,000 \mathrm{~m}^{3}$. In addition to the complex terrain and landforms, the weak management and control of the abandoned earthwork during the construction phase are also the important cause for of the large average slag quantity.

In the highway projects located in the plain rolling terrain area and the area of mountainous and hills, Guangzhou North Second Ring Expressway is the six-lane expressway with the $32 \mathrm{~m}$ wide subgrade, and its average subgrade earthwork volume and slag quantity per kilometer is respectively $165,400 \mathrm{~m}^{3}$ and $11,400 \mathrm{~m}^{3}$; the average subgrade earthwork volume per kilometer of the remaining 18 four-lane expressway projects is about $76,700 \sim 369,000 \mathrm{~m}^{3}$, and the average slag quantity per kilometer is about $5,100 \sim 49,400 \mathrm{~m}^{3}$.

\subsubsection{Relationship between the bridge and tunnel ratio, subgrade earthwork volume and slag quantity of the highways in the area of mountains and hills.}

Considering that the construction standards of Xiaomengyang-Boten Highway and Zhaotong to the highway to be supplemented are mainly for the secondary highways, and Anning-Chuxiong Expressway is mainly for extension of the secondary highways, this study only analyzes the relationship between the bridge and tunnel ratio, the subgrade earthwork volume and slag quantity according to the investigation results of the remaining 11 newly-built highways in the area of mountains and hills based on the principle of comparability. See Figure 1 and Figure 2 for the relationship between the bridge and tunnel ratio, the average subgrade earthwork volume and drag quantity of the highways in the area of mountains and hills. 


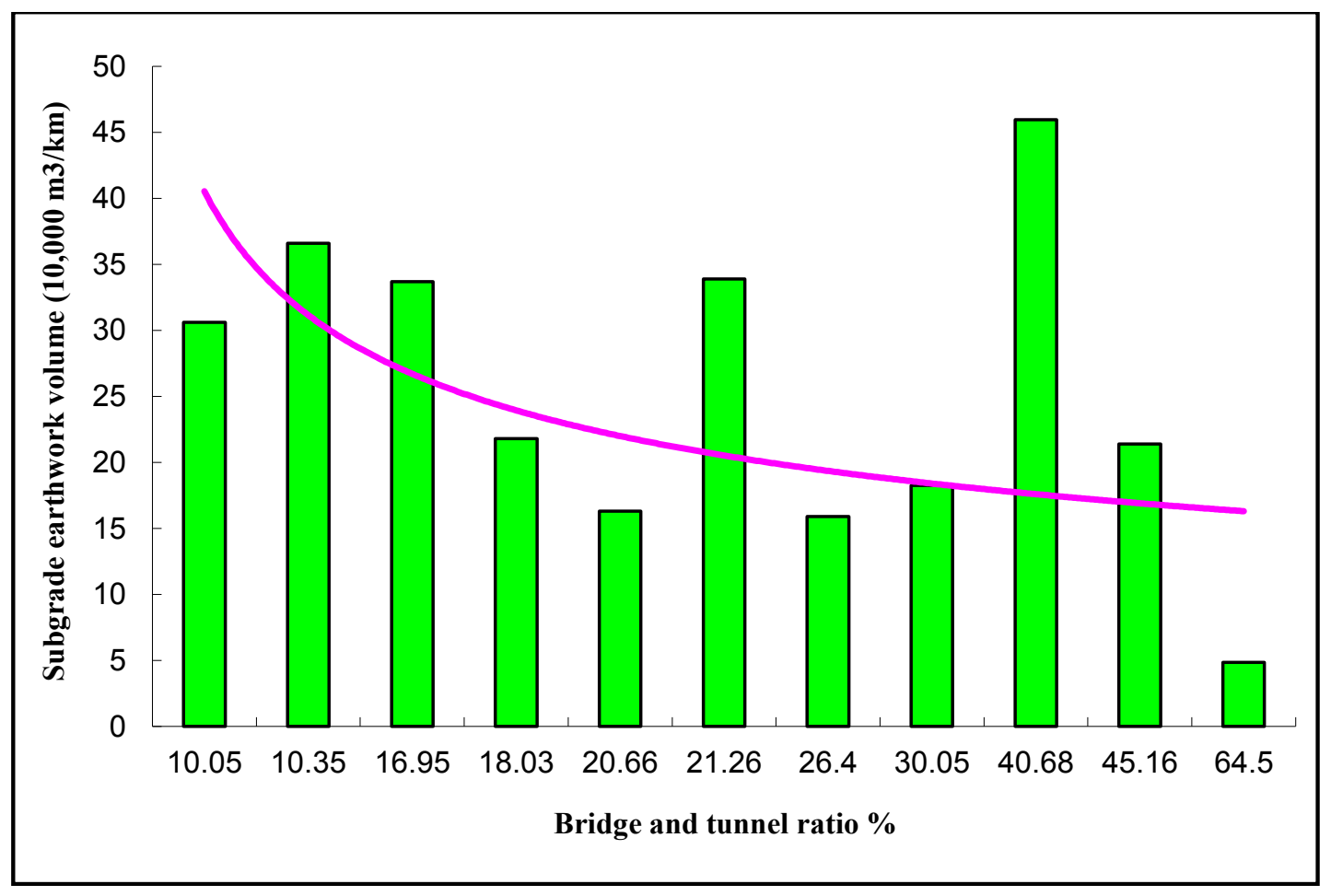

Figure 1 Relationship between the bridge and tunnel ratio and the average subgrade earthwork volume of the highways in the area of mountains and hills.

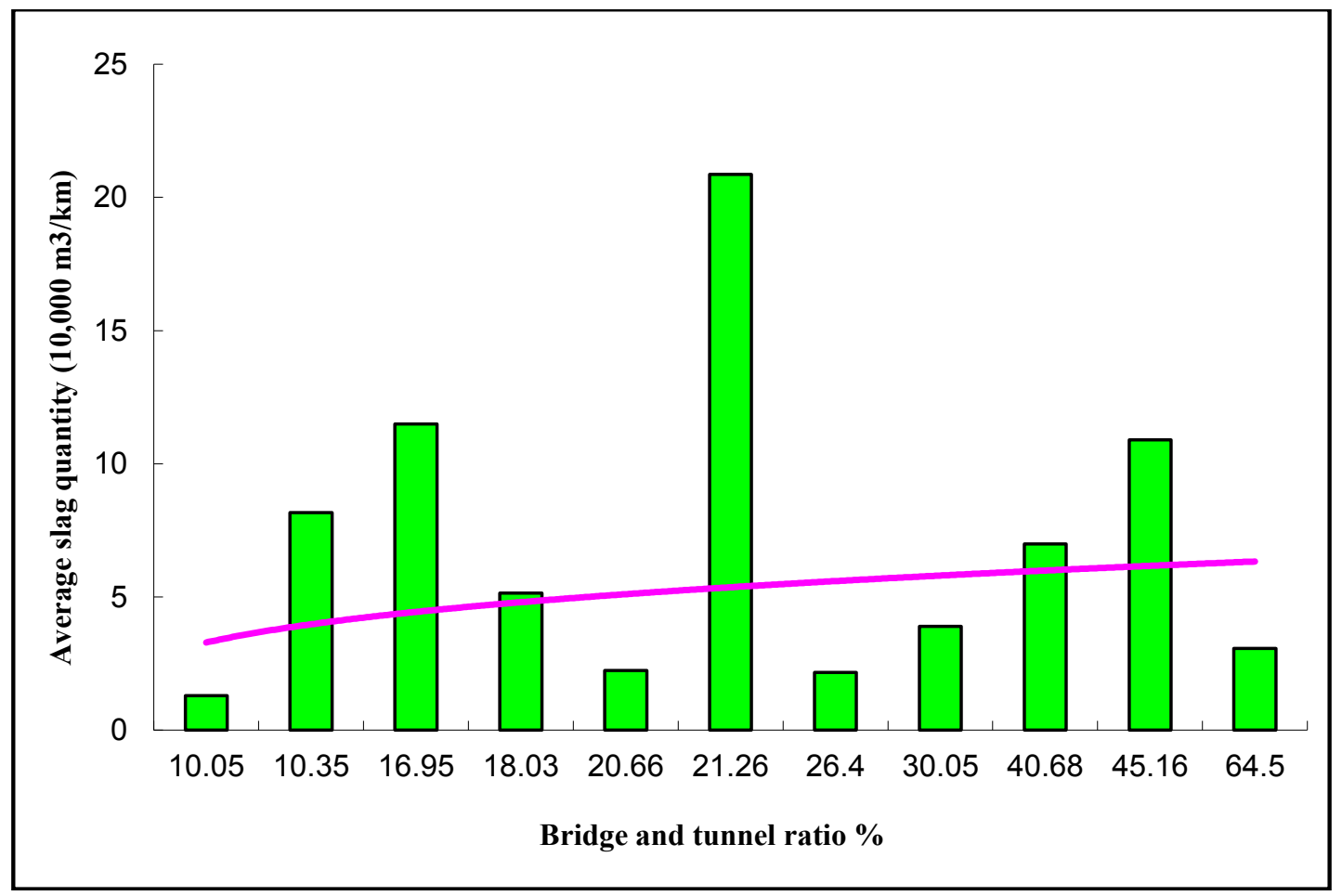

Figure 2 for Relationship between the bridge and tunnel ratio and the average drag quantity of the highways in the area of mountains and hills.

As can be seen from Figure 1 and Figure 2:

- The bridge and tunnel ratio and the average subgrade earthwork volume of the highways in the area of mountains and hills are basically in negative correlation, that is, the larger the bridge and tunnel ratio is, the smaller the average subgrade earthwork volume is;

- The bridge and tunnel ratio and the average drag quantity of the highways in the area of mountains and hills are in positive correlation, that is, the larger the ratio of bridge to tunnel is, the larger the slag quantity is.

Therefore, adopting the reasonable bridge and tunnel ratio for the highway projects in the area of mountains and hills is an important measure to reduce the subgrade earthwork quantity and the slag. 


\subsection{Characteristics of the spoil yards in mountainous highways}

\subsubsection{Number of spoil yards and floor area}

The statistical results of the number of spoil yards and floor area of the investigation project show that:

- The number of spoil yards in the highways in the plain rolling terrain area is about $1 \sim 3$ per $10 \mathrm{~km}$, and the average floor area of each spoil yard is about 0.71 4.02 $\mathrm{hm}^{2}$.

- The number of spoil yards in the highways in the area of mountains and hills is about 2 11 per $10 \mathrm{~km}$, and the average floor area of each spoil yard is about $0.36 \sim 2.62 \mathrm{hm}^{2}$; wherein one spoil yard is arranged every kilometer on Sansui-Kaili Expressway in Guizhou.

- The number of spoil yards in the highways crossing two geomorphic units of the plain rolling terrain area and the area of mountains and hills is about 1 16 per $10 \mathrm{~km}$, and the average floor area of each spoil yard is about $0.24 \sim 1.85 \mathrm{hm}^{2}$. Among them, Changde-Jishou Expressway and Changde-Zhangjiajie Expressway in Hunan and Neixiang-Xiping Expressway in Henan have the large spoil yard number per kilometer. According to the field investigation, it's caused by a large number of scattered small spoil points.

\subsubsection{Spatial location relationship between spoil yards and highways}

It can be seen from the statistical results of the spatial location relationship between the spoil yards and the highways of the investigation project:

- The spoil yards in the mountainous highways are mainly distributed within $200 \mathrm{~m}$ from the highway centerline, and the distance between most spoil yards and the highway centerline is less than $50 \mathrm{~m}$;

- There are fewer spoil yards located within the permanent land area of the highway like the interconnection area or other areas designed in combination with the embankment for slag disposal.

\subsubsection{Restoration methods of the spoil yards}

From the statistical results of the restoration methods of the spoil yards of the investigation project:

- The later restoration methods of the spoil yards in the mountainous highways include natural restoration, artificial greening, second plowing and conversion to construction land (as house site, plant land, permanent acquisition and permanent transformation into the viewing platform).

- Among the restoration methods, the artificial greening accounts for the largest proportion, followed by second plowing and then natural restoration. Among them, the proportion of the spoil yards adopting the second plowing measures is relatively large in Xinjie-Hekou Expressway, Kunming-Shilin Expressway and Songming to the highway to be supplemented in Yunnan.
The greening processes adopted by the spoil yards adopting artificial greening include artificial sowing of grass, hydraulic spraying and sowing of grass, soil replacement spraying sowing and greening, artificial planting of shrubs and tree.

\subsection{Later restoration measures and effects of the spoil yards}

According to the data survey and field survey results of typical projects, the later restoration methods of the spoil yards in the mountainous highways include natural restoration, artificial greening, second plowing and conversion to construction land (as house site, plant land, permanent acquisition and permanent transformation into the viewing platform).

\subsubsection{Recoverability of the surface slag composition in different spoil yards}

The investigation results find that:

- The spoil yards with the surface composition of pure abandoned stone and slag have no possibility of natural restoration basically due to the fact that there is no soil;

- The spoil yards with the surface composition of soil and soil-rock mixture has the possibility of natural restoration under appropriate conditions such as rainfall and temperature.

\subsubsection{Recoverability of spoil yards in different natural geographical areas}

The investigation results find that:

- The spoil yards in the southern regions with abundant rain (such as Yunnan, Guizhou, Jiangxi, Anhui, Hunan, Zhejiang, Guangdong and Qin-Ba mountain areas in southern Shaanxi) all have high natural restoration capability and the vegetation restoration process in the spoil yards can be remarkably accelerated by means of artificial greening [5-6].

- The spoil yards in arid and semi-arid areas such as Datong in Shanxi, western Inner Mongolia, and Ningxia have low natural restoration capability, and the vegetation restoration process of the spoil yards is slow even under the intervention of artificial greening and other measures.

\subsection{Water and soil loss forms in the spoil yards}

The field investigation results show that the main soil and water loss forms in the spoil yards in the mountainous highways include landslide, collapse, slippage, gully erosion and rill erosion. Many spoil yards in Fenyang-Lishi Expressway in Shanxi have landslide developed due to the lack of barriers and drainage facilities as well as the reduced stability of the loess in case of water. After the southern spoil yards are covered by vegetation, no obvious water and soil loss is found basically. 


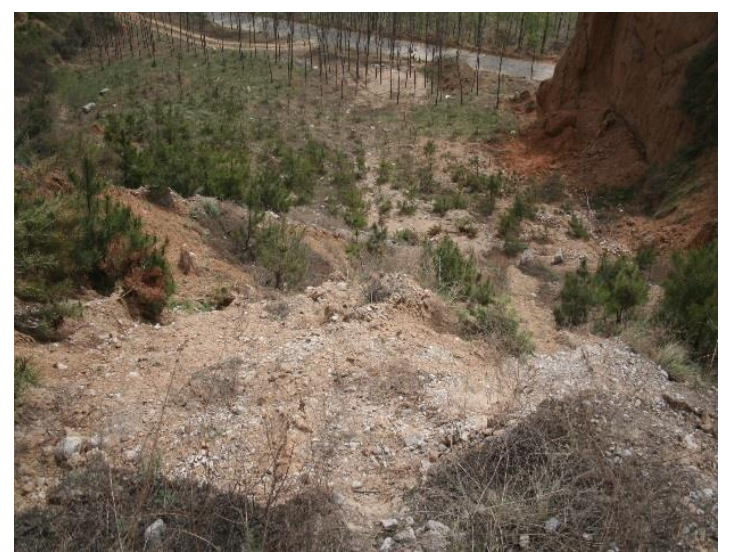

Landslide (Northwest section of Taiyuan City Belt Expressway in Shanxi)

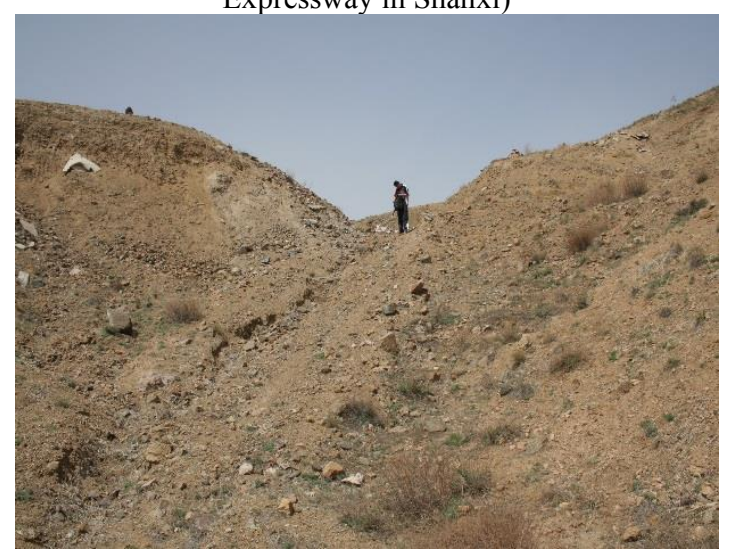

Collapse (Deshengkou-Datong Superhighway in Shanxi)
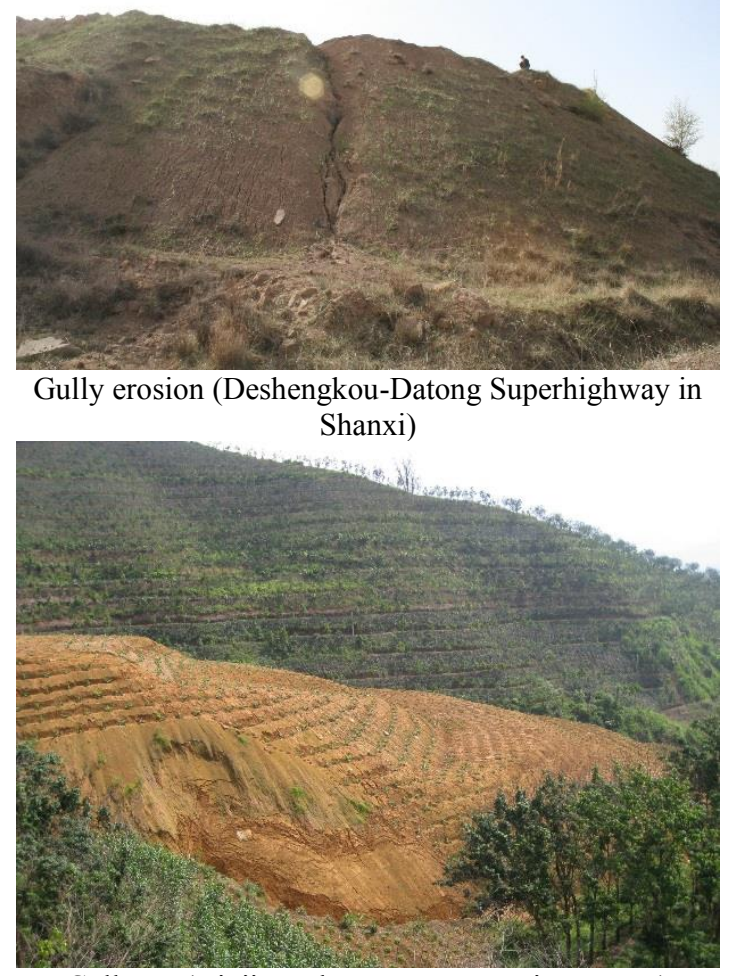

Collapse (Xinjie-Hekou Expressway in Yunnan)

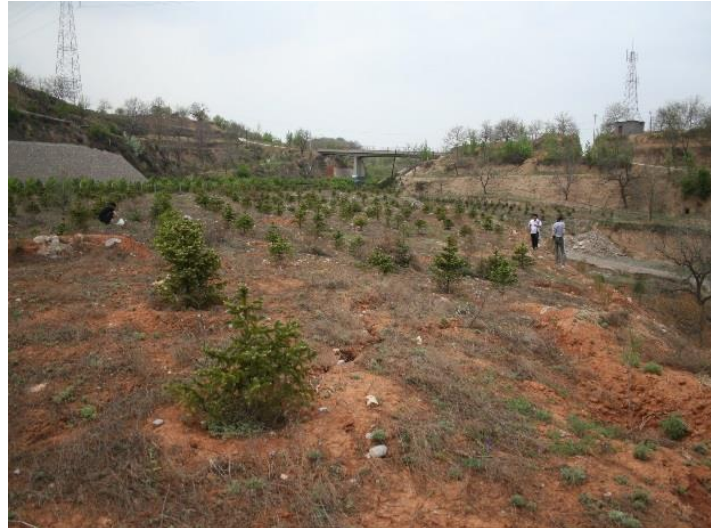

Landslide (Fenyang-Lishi Expressway in Shanxi)

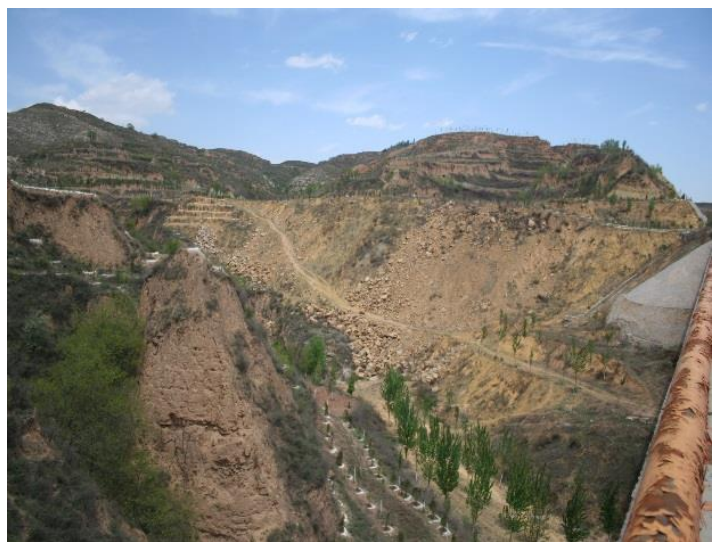

Slippage (Taiyuan-Changzhi Expressway)

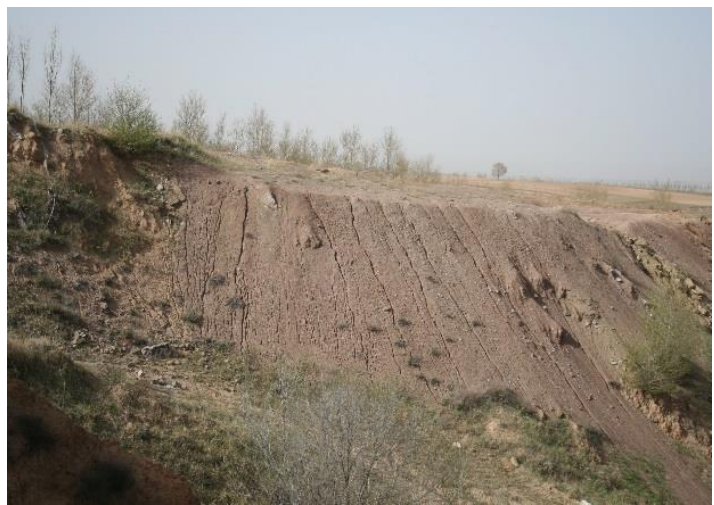

Rill erosion (Deshengkou-Datong Superhighway in Shanxi)

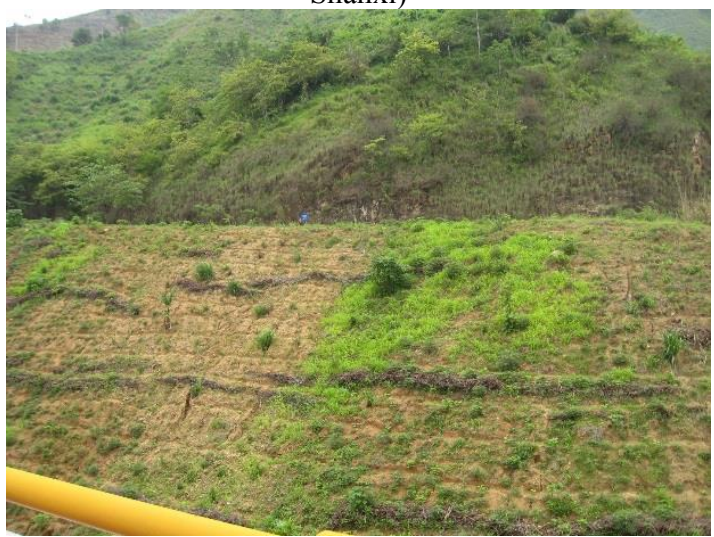

Gully erosion (Xinjie-Hekou Expressway in Yunnan)

Figure 3 Field investigation photos of the main soil and water loss forms in the spoil yards in mountainous highways 


\section{Research conclusions and suggestions}

\subsection{Conclusions}

5.1.1 Insufficient field investigation in the design phase and insufficient design depth are one of the main reasons for the large change in the site selection of the spoil yards;

5.1.2 Design and construction management measures such as selecting reasonable bridge and tunnel ratio and cross-section vertical transfer of earthwork during the construction phase are effective means to reduce the spoil yard hazard from the source.

5.1.3 The main standards and parameters for the design and construction of the spoil yards in the mountainous highways are not studied or standardized systematically, and there are no regulations for the construction quality control of the spoil yards;

5.1.4 The later restoration design and construction of the spoil yards are quite arbitrary, and there is no uniform standard for the quality inspection and assessment.

\subsection{Suggestions}

5.2.1 Incorporate the design of the spoil yards into the special design content of the highway environmental protection projects and perform critical design for the main content of the layout planning, blocking facilities, drainage facilities and restoration projects of the spoil yards;

5.2.2 List the quantities of blocking facilities, drainage facilities and restoration projects of the spoil yards into the construction bidding BOQ, or perform independent bidding and construction management with the spoil yards as the unit project;

5.2.3 Establish the earthwork cross-section transfer system to reduce the number of spoil yards and temporary land area from the source;

5.2.4 Strengthen the construction and management of temporary blocking and drainage facilities during the construction phase of the spoil yards.

\section{References}

1. Zhang Y.W., Xu W.S., Han P., et al. (2017) Application of the UAV Remote Sensing Technology in Soil and Water Conservation Monitoring in Construction Projects: A Case Study of Water Resources Allocation for the Region of North Hubei
[J]. Science of Soil and Water Conservation, 15 (2): 132-139.

2. Luo H., Zhao T.N., Peng X.F., et al. (2013), Experimental Study on Soil and Water Conservation Effect of Highway Slope Greening Covers [J]. Transactions of the CSAE, 29 (5): 63-70.

3. AleottiP, ChowdhuryR. (1999), Landslide hazard assessment: summaryreview and new perspectives [J].Bull Eng Geol Env, (58): 21-44.

4. Zhuo M.N., Li D.Q., He X.L., et al. (2003), Discussion on Ecological Restoration with Water and Soil Conservation in Highway Construction [J]. Research of Soil and Water Conservation, 10 (4): 209-211.

5. Liu H., Zhang J.M., Fu J.D., Hu H. \& Shao R. (2012), Sensitivity Calculation and Analysis of Spoil Yard Influencing Factors [J]. Safety and Environmental Engineering, 19 (6): 54-58.

6. Wang F., Li R. \& Yang Q.K., (2003) Research on Soil and Water Loss and Soil and Water Conservation in Highway Construction [J]. Highway. (S1) 